\title{
Microscopic Analysis of Heat Affected Zone (HAZ) of Submerged Arc Welding (SAW) Joint for 1018 Mild Steel Sheet
}

\author{
T. Tadavi ${ }^{1}$, B. Jogi ${ }^{2 *}$, S.Dhende ${ }^{1}$, S. Banait ${ }^{3}$, P. Wagh ${ }^{3}$ \\ ${ }^{1}$ UG Student, ${ }^{2}$ Associate Professor, ${ }^{3}$ PG Student \\ Dr. Babasaheb Ambedkar Technological University, Lonere, India \\ \{bfjogi@dbatu.ac.in, bfjogi@gmail.com\}
}

\begin{abstract}
This research presents observation of the microstructure of 1018 mild steel in the heat affected zone (HAZ) region. For SAW process various parameters are chosen such as current, voltage and welding speed. The welding experiments were conducted as per the Taguchi L9 method. The samples of 1018 MS were welded by submerged arc welding (SAW), followed by sample preparation and observation under Nikon microscope. Sample was prepared by cutting, mounting, polishing and etching method. It was observed that the microstructure of the centre of weld zone is completely different from the heat-affected zone. The few defects such as porosity, inclusion due to slag and the variation in microstructure due to temperature difference and cooling rate are observed through microscopic analysis.
\end{abstract}

Keywords: Submerged arc welding (SAW), heat affected zone (HAZ), Microscopic analysis, 1018 Mild steel

\section{Introduction}

Submerged arc welding (SAW) process uses heat generated by an electric arc established between a bare consumable electrode wire and the work piece. Since in this process, welding arc and the weld pool are completely submerged under cover of granular fusible and molten flux therefore it is called so. During welding, granular flux is melted using heat generated by arc and forms cover of molten flux layer which in turn avoids spatter tendency and prevents accessibility of atmospheric gases to the arc zone and the weld pool. The molten flux reacts with the impurities in the molten weld metal to form slag which floats over the surface of the weld metal layer of slag over the molten weld metal results: Increased protection of weld metal from atmospheric gas contamination and so improved properties of weld joint. Reduced cooling rate of weld metal and heat affected zone (HAZ) owing to shielding of the weld pool by molten flux and solidified slag in turn leads to smoother weld bead and reduced cracking tendency of hardenable steel [1].

\subsection{Principle of operation}

Submerged arc welding is adaptable to both semiautomatic and fully automatic operation. Fig.1 shows a typical setup and melting and solidification sequence of automatic SAW. In semiautomatic welding, the welder controls the travel speed, direction, and placement of the weld. The spacing, configuration and electrical nature of the electrodes may be arranged to optimize welding speed and bead shape [1,2].

\subsection{Factors affecting the characteristics of SAW weld}

Weld quality is determined by following parameters: welding voltage, welding current, welding speed, electrode composition, electrode specification (size, extension and angle) and flux. The parameters like flux, electrode composition and electrode specifications were pre-determined and kept same for the further experimental work. The welding voltage was kept constant and welding current and welding speed were varied [11].

B. Iyer, S. Nalbalwar and R. Pawade (Eds.)

ICCASP/ICMMD-2016. Advances in Intelligent Systems Research.

Vol. 137, Pp. 194-199.

(C) 2017. The authors - Published by Atlantis Press

This is an open access article under the CC BY-NC license (http://creativecommons.org/licens)es/by-nc/4.0/). 

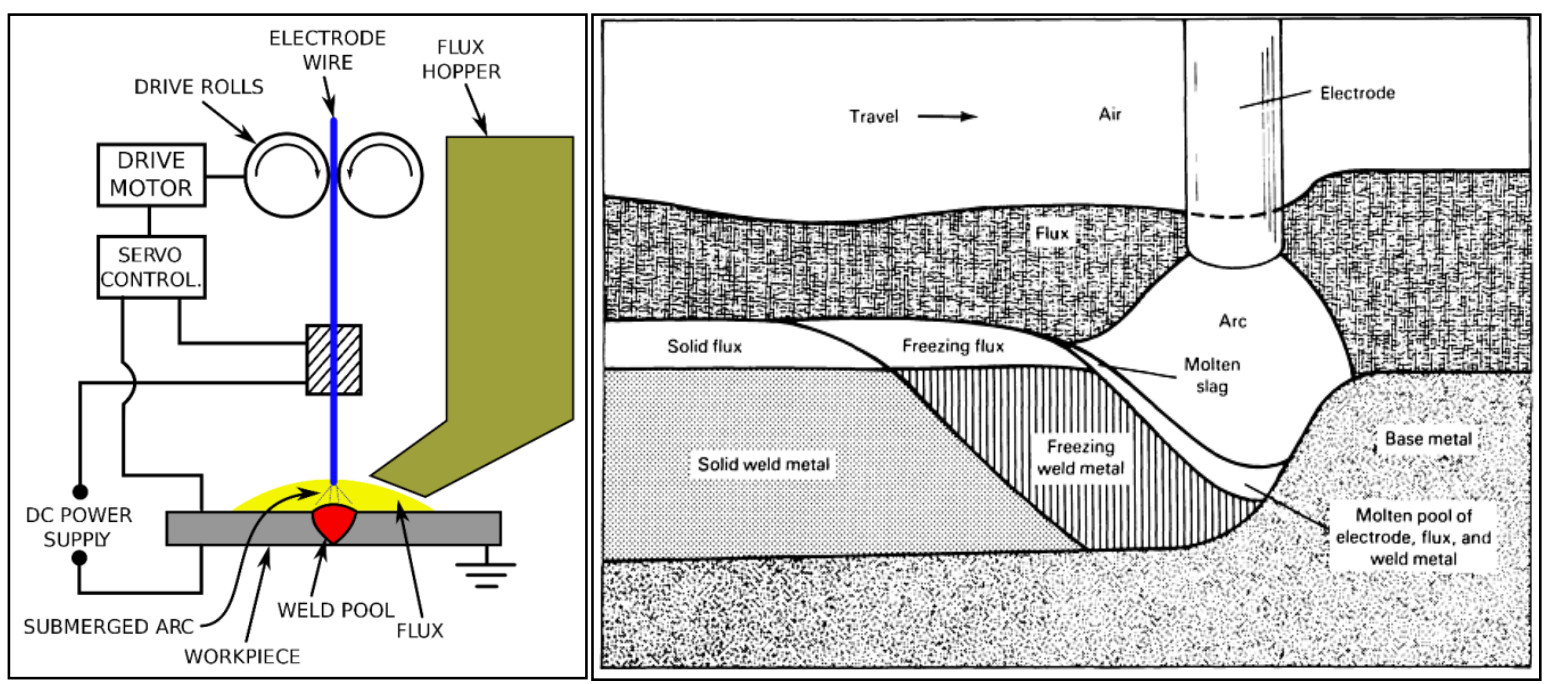

Fig. 1. Schematic showing key components and weld pool dynamics of automatic submerged arc welding setup [1]

\subsection{Weldability of steel}

Weldability is the ability to weld a material. Austenite is formed when the metal near fusion line is heated above A3 temperature. Depending on the cooling rate, the austenite formed is transformed into new different structures. It is also dependent on continuous cooling transformation diagram of the base metal. The weld becomes very hard and brittle if martensite is the product of transformation of austenite. This martensitic transformation often leads to failure of weld due to cracking.

\subsection{Microstructure of steel weld}

The actual cooling rate with which the weld cools, the composition of base metal and the flux decide the overall microstructure of the weld during transformation of austenite to ferrite. As the weld has been cooled, it is polished, etched and then observed. Three distinct metallurgical zones were observed which are the heat affected zone (HAZ), weld metal zone (WM) and the unaffected base metal (BM) [11].

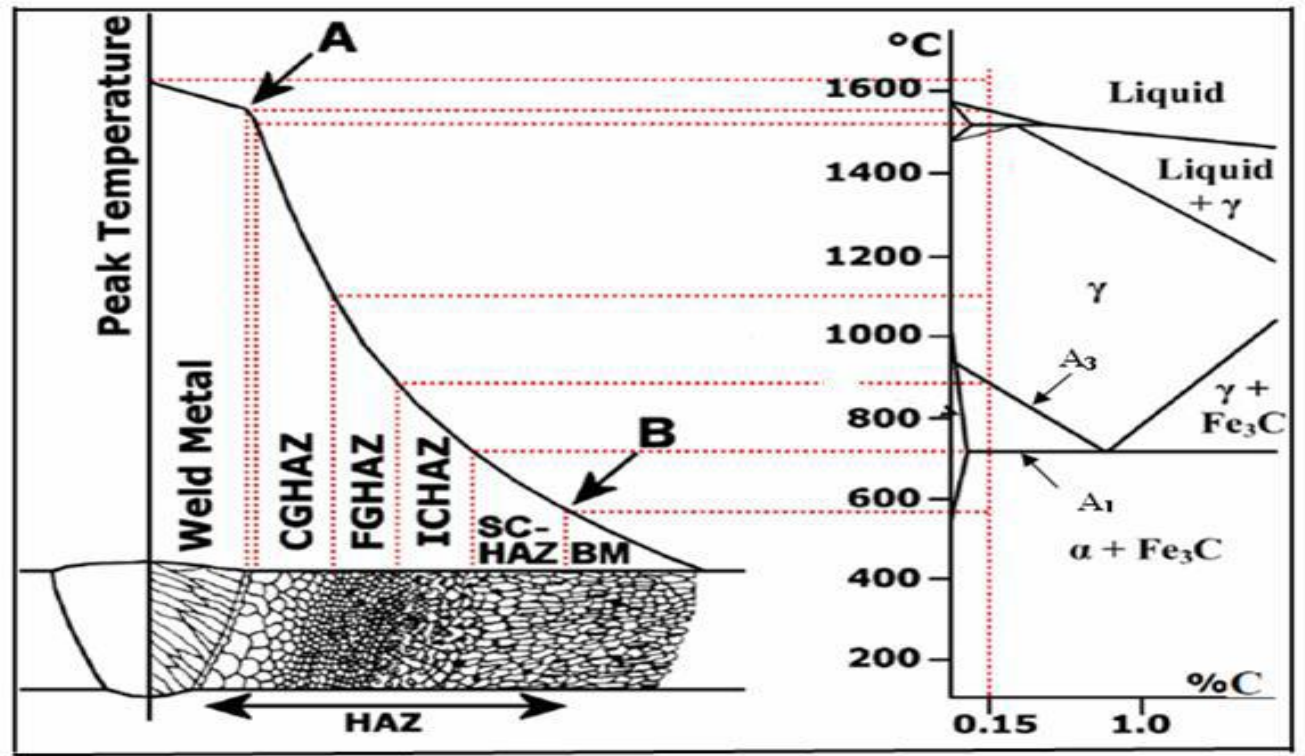

Fig. 2. Schematic diagram of the heat-affected zone [11] 
The region which lies between the weld and the base metal is called the heat affected zone (HAZ). The microstructure of the heat affected zone depends upon the peak temperature reached and the time duration spent in the temperature range of $800^{\circ} \mathrm{C}-500^{\circ} \mathrm{C}$. The constituents of the microstructure of the heat affected zone may vary from thin zones of martensite to coarse pearlite zones. Fig. 2 is a schematic illustration of the iron-iron carbide phase diagram and the heat affected zone of a welded low carbon steel. As per fig. 2, the HAZ divided into four different microstructural zones for plain carbon steel, namely, grain growth zone 1450 to $1100{ }^{\circ} \mathrm{C}$, recrystallized zone $1100{ }^{\circ} \mathrm{C}$ to $\mathrm{A} 3$, partially transformed zone A3 to A1 and tempered zone below A. The heat affected zone further subdivided into coarse grained (CGHAZ), fine grained (FGHAZ), intercritical (ICHAZ) and sub-critical (SCHAZ) zones [24].

\subsection{Microstructural products of a steel weld}

The microstructural zones were observed under optical microscope on cooling. They are grain boundary ferrite (GBF), Widmanstatten ferrite (WF) and fine grained intergranularly nucleated acicular ferrite (AF). If high cooling rates are implied we may also observe small quantities of carbides, sulfides, martensite (M) and retained austenite (RA). These all are the products of untransformed austenite. Widmanstatten ferrite is an undesirable transformation product because it leads to poor fracture toughness. The difference between acicular ferrite and bainite is that AF nucleates intragranularly on inclusions and its growth is limited by hard impingement with other AF plates which form within the prior austenite grain boundary [60]. On the other hand, bainite forms intragranularly but not on inclusions.

\section{Experimental Work}

\subsection{Materials}

The base metal is 1018 mild steel. It is use as working material. The base metal contains iron (98.81-99.26\%), carbon $(0.18 \%)$, manganese $(0.6-0.9 \%)$ and phosphorus $(0.04 \%)$, sulphur $(0.05 \%)$. Electrode is automelt $\mathrm{EH}$ 14(C-0.07, Mn-1.5, Si-0.3, S-0.003, and P-0.03).

\subsection{SAW of Metals}

The weld joints performed and analysed in this work were shop produced by the small scale industry Personnel located in Satara. The base plates were cut into approximately $200 \mathrm{~mm}$ x $65 \mathrm{~mm}$ x $10 \mathrm{~mm}$ strips, cleaned with a steel wire brush and compressed air before they were submerged arc welded using an ESAB Electric Welding machine and EH 14 welding wire electrode and ESAB OK 10.72 flux. The welding is done by using closed circuit voltage and negative polarity with $2 \mathrm{~mm}$ root gap. The procedure started by using two mild steel plates and maintaining a gap of $2 \mathrm{~mm}$ for a total of 9 runs using Taguchi $\mathrm{L}_{9}\left(3^{3}\right)$ method. The variable parameters chosen for 9 experiments were current (300, 350 and 400 ampere), voltage (28,032 and $36 \mathrm{~V}$ ) and welding speed (30, 40 and $50 \mathrm{~mm} / \mathrm{min})$ respectively.

\subsection{Sample preparation and Mounting}

The prepared SAW weld samples are used as test samples measuring approximately $20 \mathrm{~mm}$ long x $15 \mathrm{~mm}$ wide were cut transverse to the weld joint with an abrasive cutter. The material was mounted on hot mounting machine by using bakelite powder. The similar process was followed for mounting a total of 9 samples. All cut samples are clean using grinder wheel to remove metal bur and unwanted metal. The mounted samples were polished using automatic polishing machine by using different polishing papers of grades 80, 220, 320, 420, $600,1000,1200$ and 1500. These polishing papers are made of silicon carbide. In the second step, polishing was done using 1.5 and $1 \mu \mathrm{m}$ diamond paste on a nylon cloth. The samples were lubricated with aerosol spray between each polishing step. The polished samples were etched in standard $5 \%$ Nital (5 vol. \% nitric acid and 95 vol. \% alcohol) solution for about 2 to $3 \mathrm{~s}$ to reveal the weld profile showing the base metal (BM), the heat affected zone (HAZ) and the weld metal (WM).The prepared samples were dried by blowing hot air. 

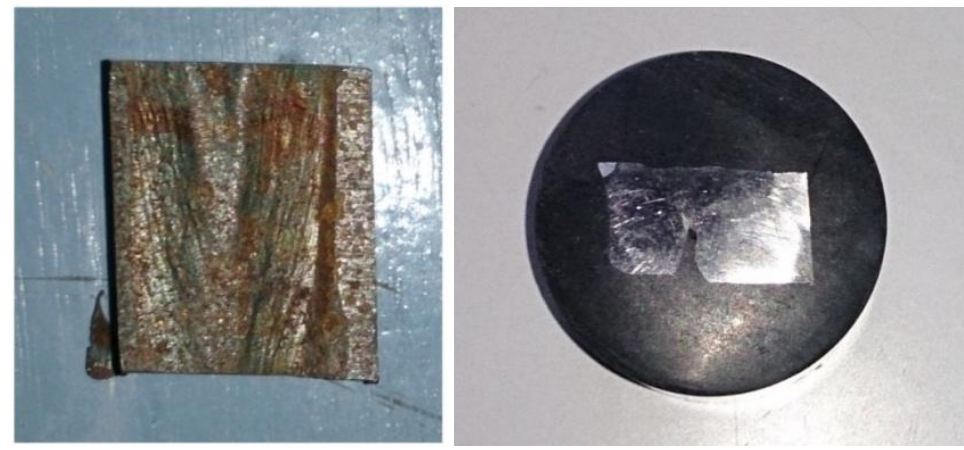

Fig. 3. Cut metal piece and Mounted sample

\section{Results and Discussion}

Microstructure is one of the mechanical properties which are helpful for checking out the structure of the material. Weld specimens can involve wide variations in material hardness across the specimen either because of a phase changes during welding or because the joint incorporates dissimilar metals. The weld metal may contain hard precipitates or some indigenous weld defect.

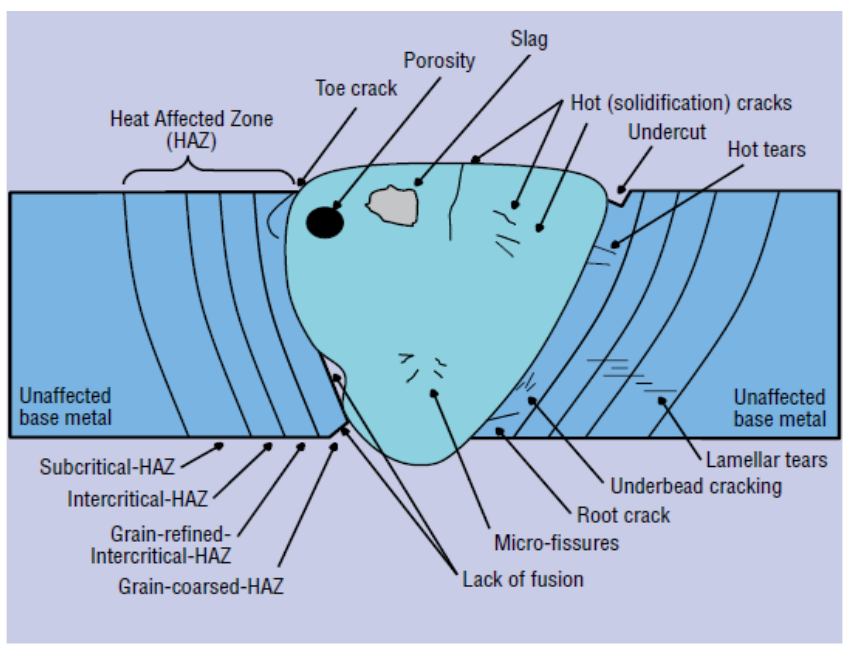

Fig. 4. Welding zone [1]

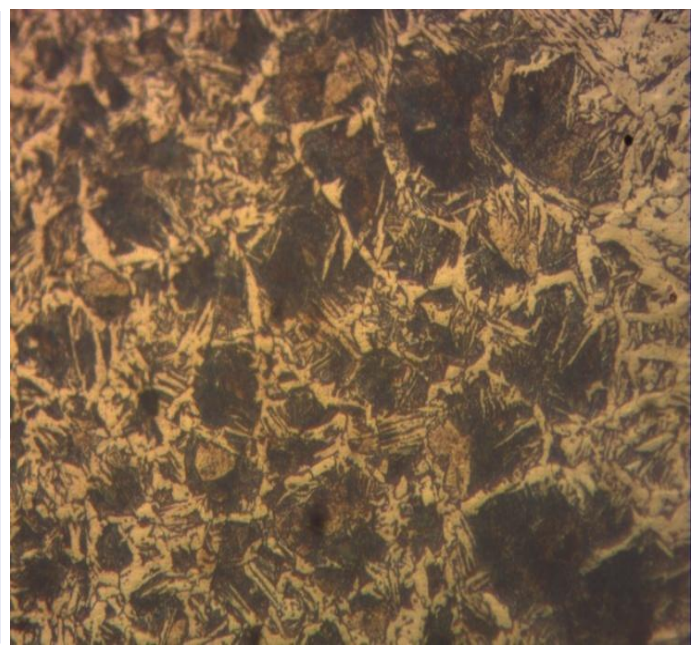

Fig. 5. Microstructure of base metal

\subsection{Base metal}

Typical microstructure of steel (base metal) is composed of ferrite and small regions of pearlite $\left(\alpha-\mathrm{Fe}+\mathrm{Fe}_{3} \mathrm{C}\right)$ at grain boundary edges and corners as shown in Fig. 5. Further, Fig. 6 shows the macro section through deep penetration fillet weld in carbon steel. The boundary lines are clearly observed in this image.

\subsection{After Welding}

Optical microscope was used to observe the microstructure of welded steel sheets. The photograph of nearest region to HAZ shows the elongated ferrite grains, this happens due to direction of heat flow. It is observed that large grains are present near the fusion line and they are oriented along the direction of large heat flow $[10,11]$.

The microstructure of heat affected zone is shown in fig. 8. It shows some colonies of pearlite and Widmanstatten ferrite. Adjacent to fusion zone, there is a coarse grained region of heat affected zone. The grains in this region are somewhat larger than that of the ones in base metal.

We can see that the centre of the weld is different from other zones from Fig. 8. It is due to the presence of pseudo grains and microstructural heterogeneity which has been resulted from faster cooling rates. It has been 
found that this zone mainly contains ferrite and some colonies of pearlite. The microstructural heterogeneity mainly arises due to the temperature gradients and the chemical gradients that occur during the cooling [11].

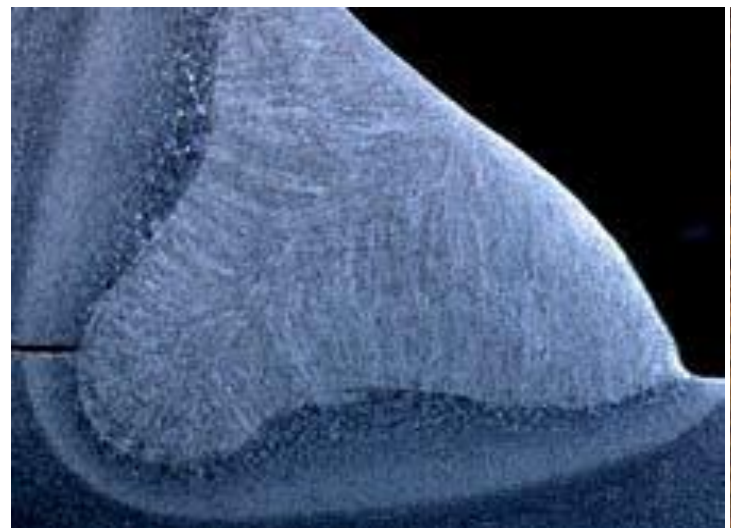

Fig. 6. Sample after etching

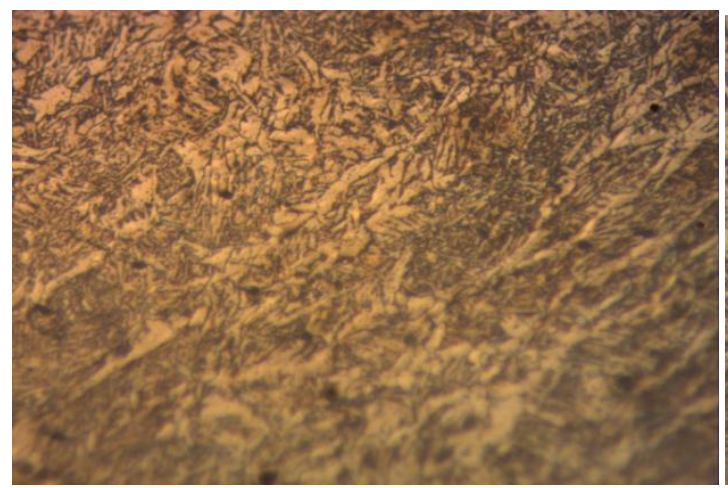

Fig. 8. Microstructure of HAZ

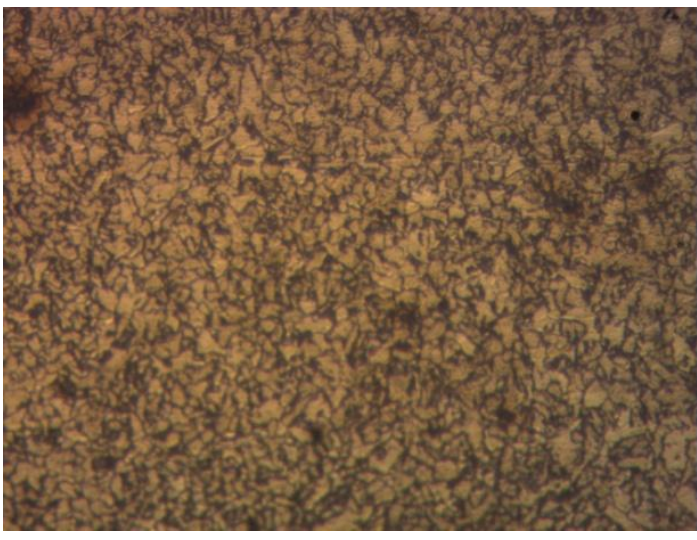

Fig. 7. Microstructure of HAZ

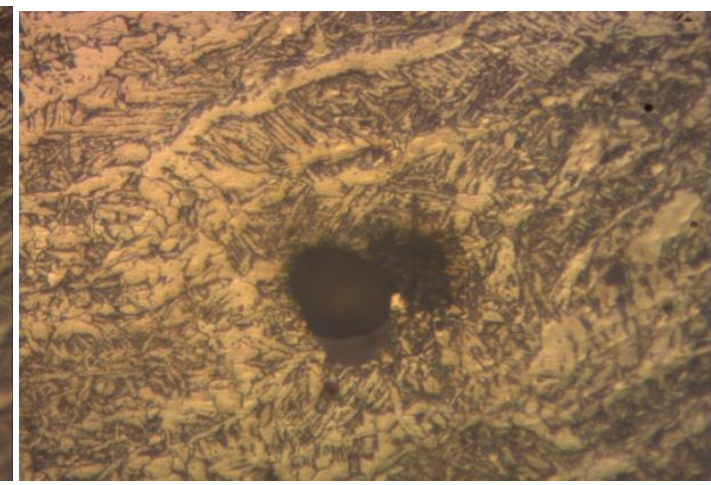

Fig. 9. Defect in Microstructure

\subsection{Defects}

Variation in microstructure due to porosity in HAZ can be seen in Fig. 9. The black spot in the microscopy represents the porosity. However, variation due to slag in HAZ can be seen in Fig. 10. The variation at surface in heat fusion zone (HFZ) due to temperature difference and cooling rate is shown in Fig 11. These are the basic defects observed in the microscopic analysis of HAZ.

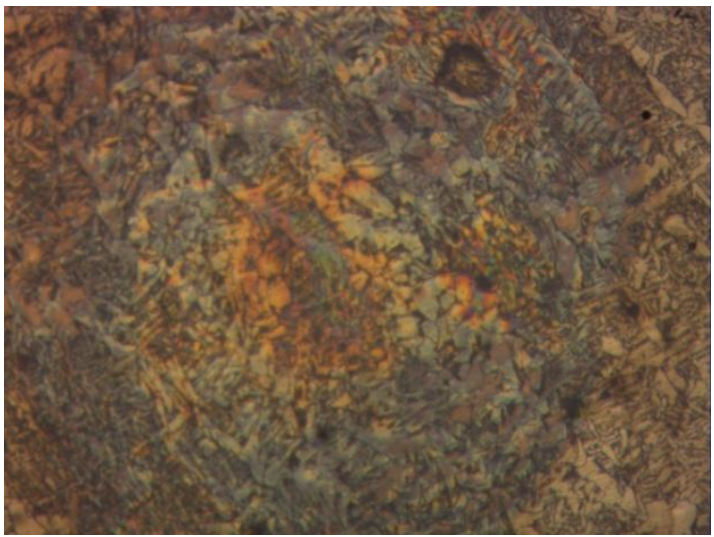

Fig. 10. Defect in Microstructure

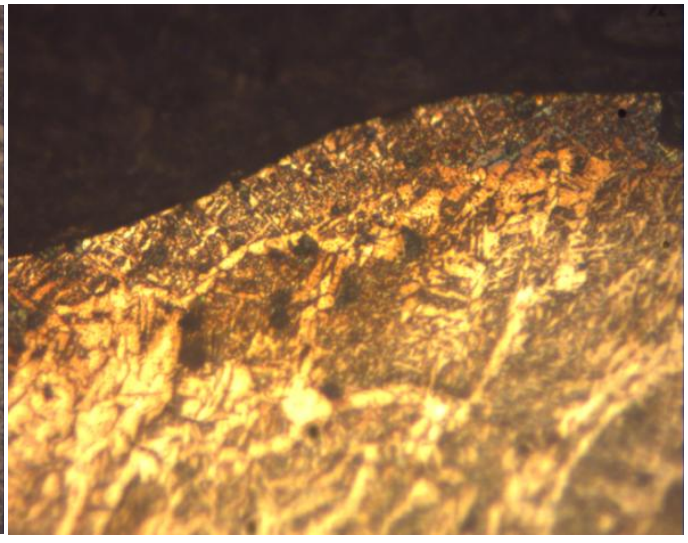

Fig. 11. Variation in Microstructure of HAZ due to temperature diffrence and cooling rate 


\section{Conclusions}

The microstructures in different HAZ are determined from the base metal to the weld metal. The microstructure of the centre of weld zone is completely different from the heat-affected zone. HAZ contains ferrite, large grains of ferrite and colonies of pearlite. No formation of martensite takes place at HAZ. Few defects like porosity, inclusion due to slag are observed.

\section{References}

[1]. Cary H.B., Modern Welding Technology, 2nd edition, Prentice-Hall, 1989.

[2]. Shan-ping Lu, Oh-Yang Kwon, Tae-Bum Kim, Kwon-Hu Kim, Microstructure and wear property of Fe-Mn-Cr-Mo-V alloy cladding by submerged arc welding, , Journal of Material processing technology 147 (2004), 191-196.

[3]. Operation and Maintenance Manual for AUTOMATIC SUBMERGED ARC WELDING SYSTEM, MODEL: MAESTRO 1000(I), Ador welding limited, 7-9.

[4]. Choudhari Nirmalendu, Padhay Asishbandy \& Rudrapati Ramesh, Design optimization of Process Parameters for TIG welding based on Taguchi Method, Jadavpur University, Kolkata - 700032, India.

[5]. Tusek J. and Suban M., High-Productivity Multiple-wire Submerged-Arc Welding and Cladding with Metal-Powder Addition, University of Ljubljana, Slovenia(1995), 2-3.

[6]. ASM Handbook, Volume 6 - Welding, Brazing and Soldering, ASM International (1993), 618-641.

[7]. Y. S. Tarng \& W. H. Yang, Application of the Taguchi Method to the Optimization of the Submerged Arc Welding Process, Materials and Manufacturing Processes, 13:3(1998), 455-467.

[8]. Kou, S., Welding metallurgy, 2nd edition, 2003, John Willey and Sons, Inc., USA, ISBN 0-471-434914.

[9]. Fu, G., Tian, F., Wang, H., Studies on softening of heat-affected zone of pulsed current GMA welded Al-Zn-Mg alloy, Journal of Materials Processing Technology, 2006, Vol.180, p 216-110

[10]. E. Bayaraktar, D. Kaplan, L. Devillers and J. P. Chevalier, "Grain Growth Mechanism during the Welding of Interstitial Free (IF) Steels," Journal of Materials Processing Technology, Vol. 189, No. 1 3, 2007, pp. 114-125.

[11]. James Amani, Effect of submerged arc welding parameters on the microstructure of SA516 and A709 steel weld, University of saskatchewon suskatoon, August 2011. 